\title{
Contextual Weather and Climate Broadcast System: Case for Nganyi Community Farmers in Kisumu
}

\author{
Dr. Daniel Orwa Ochieng ${ }^{1}$, Sharon Wanjiru Kamau ${ }^{2}$ \\ ${ }^{1}$ Senior Lecturer, University of Nairobi. \\ dorwa@uonbi.ac.ke \\ ${ }^{2}$ Phd Student, Univserity of Nairobi. \\ Kamau_sharon@yahoo.com
}

\begin{abstract}
Mobile phone ownership has seen a steady increase in Kenya in the last five years and currently stands at 28.08 million mobile phone subscribers spread throughout the country. With poor road infrastructure, the mobile phone has become invaluable in reaching many people and can be useful in broadcasting information such as in education, health, agriculture and many other sectors. Previous survey and analysis indicates that implementation of technology is one of the key effectors of turnaround of rural economies. The main challenge that lies ahead is one of strengthening the innovation capabilities of African in order to be able to successfully address negative impacts caused by climate change and achieve broader economic growth and development.
\end{abstract}

\section{INDEXING TERMS/KEYWORDS}

Indigenous weather prediction, scientific weather information, integrated traditional and scientific knowledge, end users as application developers.

\section{ACADEMIC DISCIPLINE AND SUB-DISCIPLINES}

Information Systems - ICT4D

\section{SUBJECT CLASSIFICATION}

ICT in Agriculture

\section{Council for Innovative Research}

Peer Review Research Publishing System

Journal: International Journal of Management \& Information Technology

Vol. 7, No. 2

editor@cirworld.com

www.cirworld.com, member.cirworld.com 


\section{INTRODUCTION}

Like other regions of the world, Africa and Kenya in particular is a victim of climate change that emanates from global warming. The negative impacts associated with climate change are also compounded by many factors, including widespread poverty, human diseases and high population density, which is estimated to double the demand for food, water, and livestock forage within the next thirty years. Nevertheless, despite the technological advances in the use of modern scientific equipment to predict and manipulate weather, the study posits that scientific methods of weather forecasting are flawed, to some extent. It shouldn't be forgotten that from time immemorial, indigenous Africans relied heavily on close observations on environmental phenomena in regards to weather forecasting. This study looked at the Nganyi community farmers in Western Kenya who have a well-established traditional indigenous weather and climate prediction system through their rainmakers. The rainmakers of the Nganyi community together with the Kenya Meteorological department in a project led by IGAD Climate Prediction Center (ICPAC), have devised ways of combining traditional and scientific weather prediction methods to combat the effects of climate change without neglecting the heritage of the Nganyi people. Hence this study attempts to answer the following research questions; can creating knowledge alliances create better communication of weather and climate information? Can weather forecasting systems be made more effective by linking indigenous rainmakers' knowledge and meteorological science? What technologies can be incorporated to develop weather and climate broadcast system for the Nganyi community farmers? The aim is to bridge the gap in reducing vulnerabilities in communities who have available good western science on weather predictions and indigenous knowledge forecasts. The assumption is that scientific findings and indigenous knowledge are complementary and seek to overcome the false dichotomy that these two ways of knowing were in opposition.

The methodology was guided by a process framework of integrating scientific and indigenous weather information through community engagement, identification of vulnerable factors, Identification of indigenous and scientific strategies and eventually, development of an integrated strategy. Data collection was done through semi-structured questionnaires, contextual enquiries and observation. A design report was generated from analysis of collected data. Use case diagrams and sequence diagrams were used to conceptualize the designed system.

The Nganyi community farmers' weather and climate broadcast system which was created by looking at end users as application developers. The local people were made to understand the technologies, specific decision-making situations and design requirements for their solution development.

The results were analyzed by incorporating a technology acceptance model - Unified Theory of Acceptance and Use of Technology (UTAUT). From observational analysis done during testing of the broadcast system and previous research data, it was noted that technology availability was low in rural communities and rural businesses. Hence as we dealt with information, the norms and practices of rural farm owners in seeking and managing crop and farm information and their communication patterns was found to be important to understand their adoption decisions to thus meet the information gap.

In summary, through an in-depth study of Nganyi community farmers and a comprehensive analysis of the results in a multi-disciplinary way, the researchers were able to identify information needs and perceptions of users which guided this study to develop a mobile phone application for rural farmers in the local context.

The greatest achievement of this research work was the involvement of critical stakeholders in development and subsequent validation of the Weather and Climate Broadcast system that is useful in the rural context. It was established that the Nganyi Community Weather and Climate Broadcast system met this need effectively. The study justified that a major objective of forecasting is to unmask fate and inform the current on timely strategic interventions that will mitigate the adverse events of the predicted phenomenon, by informing policies and supporting the end user of such information to adopt accordingly.

Despite methodological challenges, the researchers' experience suggests that local knowledge has tremendous potential in providing very systematic, local, and detailed observations over a given period of time. These observations can contribute best both in and of themselves and as hypotheses for further research, as presented in this thesis.

\section{COMMUNITY ENGAGEMENT}

In building an ethical research relationship with the indigenous communities in Kisumu it was this latter point that was particularly essential, as for the local people 'knowledge for knowledge sake [is] a waste of time' (Meyer cited in Louis, 2007 , p. 131): in other words, if research initiated from outside a community does not benefit the community in any way then it should not be carried out (Louis, 2007). In initiating such a first step with a community -in this case with Nganyi community of Luanda in Kisumu (affected by droughts and flooding) -and following in line with local cultural traditions, discussions were first held with community elders regarding the proposed project and whether they felt that such a process may assist them in identifying a potential strategy to reduce their vulnerability. The community elders then called a meeting with the majority of community members in attendance. The meeting was an opportunity for villagers to discuss important issues regarding the impact of drought and flooding concerning both the researcher and various other stakeholders, including the government and NGOs. A large community meeting such as this presented an opportunity not only for a group discussion of the disaster issues and risks of the community but also for the researcher to probe with specific questions through Questionnaires and Contextual enquires. The meetings also enabled a discussion with the villagers regarding the potential research program what it would entail and what the expected outcomes were, while allowing villagers to explain their community in detail and point out specific topics/issues that were of concern to them. Having received a detailed outline of the research and discussed issues of concern, this then enabled the community to 
make an informed decision about participation and therefore to take ownership of the specific project. This decision was made in the absence of the researcher, thus enabling the community to analyze and further discuss in detail the positives and negatives of their involvement with such a project. Each work group session was attended by community representatives, young and old, and then presented to the community as a whole to triangulate information. During this stage, the researcher also aimed also identifying the people who will use the product, what they will use it for, and under what conditions they will use it (E. Burkman, 1987). In order to do this, participants included in the sample were selected. Members of the Nganyi clan are renowned rainmakers among the Abaluya and the Luo communities. The capability to make rain is inherited in the family. The Nganyi rainmakers have mastered the winds and associate good and bad rainfall seasons with particular wind direction. The rainmakers use nature to monitor and choose an appropriate time to make rain. A visit to the shrine of Nganyi and discussions with elders, who are the heads of the rainmakers association, revealed that the tradition is still very popular in the community. This community consists of mainly of subsistence farmers. A study with these additional persons in the sample provided information that helped in understanding how underlying agricultural practices, social factors, cultural issues and legislative issues affect the sample population. During the four day interaction time spent at the participants' homes and in sharing their activity, the researcher captured data from 42 respondents to provide breath of data. One of our key objectives in working with the Nganyi is to make weather information available and accessible at the local level. Many local communities are confused by modern meteorological information and are unable to interpret the technical language in a way that applies to their own lives. By contrast, the Nganyi's community-based predictions seem more relevant. Data Collection was done using two different methodologies:

\section{Contextual inquiries and Observation}

Contextual inquiry involved collecting detailed information about farmers' work practice by observing and interviewing the user while they actually work. The researcher stayed in the background and let the user lead the situation as much as possible. This means that researcher formed a partnership with customer, i.e., learning (but not doing) as an apprentice while the customer is the master of the work. This helps the researcher understand the customer's work. The goal was to understand how and why something is done or why something is not done.

\section{Semi-structured questionnaires}

A structured interview (also known as a standardized interview or a researcher-administered survey) is a quantitative research method commonly employed in survey research. The aim of this approach was to ensure that each interviewee was presented with exactly the same questions in the same order. This ensured that answers were reliably aggregated and that comparisons were made with confidence between sample subgroups or between different survey periods.

In this case, the data was collected by an interviewer rather than through a self-administered questionnaire. Interviewers read the questions exactly as they appear on the survey questionnaire. The choice of answers to the questions was often fixed (close-ended) in advance, though open-ended questions were also being included within a structured interview. A structured interview also standardized the order in which questions are asked of survey respondents, so the questions were always answered within the same context (Westburn 2002).

\section{IDENTIFICATION OF VULNERABILITY FACTORS}

In this stage the researcher aimed at discovering the intrinsic factors that had the largest impact on the community's vulnerability. The researcher also aimed at generating and describing interesting hypotheses of the environment of the key participants of the study. (E. Burkman, 1987). Inspiration for the hypotheses were drawn from studying the user context data collected during the field studies of the data collection stage as well as study of related work. After studying the user context transcribed from the field studies conducted, the results accumulated from the user context were summarized in a design report. Analysis of data was done at the individual level using the SPSS software over a period of two weeks. The individual level offered data that was the background with which the design report was based upon.

\section{Design Report}

Looking at the results from primary research data collected, the first notable thing is the age of the respondents. The ages were evenly distributed from 16years - 61+years. It was encouraging to note that at least $90 \%$ of the respondents had received formal education. Only $5 \%$ of the respondents had no formal education and $5 \%$ had Tertiary education. However, this clearly presented a challenge and opportunity to software developers. For one, the research revealed that despite these seeming good levels of education; only $10 \%$ felt they could comfortably read English. As such, a language module in the design of the weather and climate system or use of other languages other than English was considered. In view of this, there was need for localization of mobile user information to meet the unique needs of rural users. Encouragingly, $99 \%$ of the respondents indicated they had access to a mobile phone. Most of the mobile phones in use however had features that only allowed the user to make or receive calls and access the phonebook only. Herein lay a challenge that respondents needed access to mobile phones with additional features and needed to be trained on these features. With the large number of respondents having formal education, it was encouraging to see that they still had access to indigenous weather and climate information. $57 \%$ of respondents indicated that their main source of weather and climate information at the stage of preparing land was from the Village Rainmaker. This same group, indicated that they also got scientific information from Kenya Meteorological Department. This showed that weather and climate information is available and accessible to respondents. However, it was discouraging to note that $75 \%$ of respondents were opting not to use either the rainmaker or the scientific information sources for planting. Weather and climate information is crucial when deciding to plant as when it is done too early, the seeds are destroyed by weevils and late planting means low harvest leading to lower food provisions. In as much as the weather and climate information is available is not accessible, it was not being used. Climate and weather information was from observation during weeding and harvesting. As the planting season progressed, neither the indigenous nor scientific weather sources of information i.e. the Rainmaker and Kenya 
Metrological Department were used. Weeding was conducted continuously after planting and before harvesting. It was discouraging to note that decisions on weeding and harvesting could only be done when the farmer was present to observe the changes in the weather and his crops. There was need for crucial prediction information to be accessible and used by the farmers. Information on the rainfall intensity, length of dry spells between rainfall, if any, rainfall after the dry spell and its intensity are necessary in deciding whether to plant again and what crop to plant. This information was not being used by the farmers to make informed decisions. Reasons for not accessing and using weather and climate information were varied. $65 \%$ indicated that when the information was being conveyed, they were not available. The rainmaker announcements were done during community meetings and so most times respondents were not available to attend. $16 \%$ respondents indicated that they missed the radio and television broadcasts. And $19 \%$ indicated that when the broadcast were made, they did not understand. It was noted that information received on weather and climate conditions through their various means was deemed by respondents are being $50 \%$ quite accurate. $58 \%$ Respondents indicated that weather and climate information was available on a daily basis. Out of the $58 \%$ respondents that could access weather and climate information on a daily basis, 53\% found the information quite relevant. It was noted that although $90 \%$ respondents had received fair amount of formal educated, $40 \%$ preferred to communicate in Kiswahili and another $40 \%$ preferred to communicate in Luhya.

\section{IDENTIFYING INDIGENOUS AND SCIENTIFIC STRATEGIES USED BOTH PAST AND PRESENT FOR DISASTER RISK REDUCTION}

Step Three involved communities identifying past and present, indigenous and scientific strategies used to cope with intrinsic effects and ultimately hazard(s). Communities divided themselves into working groups with each identifying a topic incorporating disaster risk reduction strategies such as land use planning or housing construction. This was a one day discussion forum carried out by the community guided by the researcher. This was an initiative carried out by the community showing their ownership of the project. Essential in this process was working alongside community elders who are often highly respected for the knowledge they hold of indigenous strategies used in the past-of which the younger generation may know very little. This was especially important in this community in Luanda-Kisumu where the villagers took the initiative to ensure that there were village elders alongside youths in each of the groups discussing indigenous and scientific strategies. This, alongside further triangulation of data with the whole community in discussion together, ensured that all knowledge bases were covered in relation to the different research areas.

Disaster risk reduction strategies are often embedded within community life, becoming a normal part of the daily or seasonal routine, so this step involved intense discussion to ensure that all strategies were determined. Upon establishing strategies, information was triangulated with the whole community to ensure that no single strategy was excluded. It was noted that, while the community was able to identify those strategies already in existence within the community, further elaboration upon the framework and more time available would have allowed for the incorporation of additional stakeholders and ultimately further knowledge available from outside of the community. As outlined in the introduction, the scientific strategies consisted of knowledge which originated outside of the community which the communities were able to access. This enabled communities to move ahead with an integrated strategy using existing knowledge in a more effective manner to reduce their risk to hazards

\section{DEVELOP INTEGRATED STRATEGY}

This was a participatory process facilitated by the researcher to analyze vulnerability levels, specific strategies identified to deal with this, and the move forward with an integrated strategy to reduce their vulnerability. At this stage new knowledge could be developed leading to a new strategy.

Focus areas: Key focus areas were identified from findings from the study as intrusive in guiding development of a prototype.

\section{Sustainability}

- Both scientific and indigenous sources of information are available to this community - the broadcast system should therefore tap into other databases and information sources of weather and climate

- Climate and weather information is available but not always accessible to all the Nganyi Community farmers - the broadcast system should include a mobile phone application that should send messages to i. Equitability all farmers whose names and mobile phone information is stored in an existing database.

- Climate and weather information not understood - the broadcast system should interphase with a language module that translates broadcast information into the local language-Kiswahili and Luhya

ii. Stability (see Table 1)

Table 1: Observed best times for harvesting

\begin{tabular}{|l|c|c|c|c|c|c|c|c|c|}
\hline & Maize & Beans & Millet & Tomatoes & $\begin{array}{c}\text { Kales - } \\
\text { sukuma } \\
\text { wiki }\end{array}$ & Potatoes & $\begin{array}{c}\text { Groundn } \\
\text { uts }\end{array}$ & $\begin{array}{c}\text { Banan } \\
\text { a }\end{array}$ & $\begin{array}{c}\text { Yam } \\
\text { s }\end{array}$ \\
\hline No. of respondents & 15 & 13 & 3 & 1 & 1 & 7 & 1 & 3 & 1 \\
\hline & $\%$ & $\%$ & $\%$ & $\%$ & $\%$ & $\%$ & $\%$ & $\%$ & $\%$ \\
\hline
\end{tabular}




\begin{tabular}{|c|c|c|c|c|c|c|c|c|c|}
\hline When rain is moderate & 73 & 77 & 67 & 100 & & 100 & 100 & & \\
\hline Most rain & 73 & 46 & 67 & & 100 & 71 & & & 100 \\
\hline Long rains & 60 & 69 & & & & 86 & & 100 & \\
\hline During dry season & 27 & 31 & & & & & & 100 & \\
\hline $\begin{array}{l}\text { When the rain } \\
\text { immediately starts }\end{array}$ & 20 & 23 & 33 & 100 & & & 100 & & \\
\hline $\begin{array}{l}\text { After the first crop then } \\
\text { the second follows }\end{array}$ & 20 & 23 & 33 & 100 & & & 100 & & \\
\hline Moderate temperatures & 20 & 23 & & & & 14 & & 67 & \\
\hline Moderate humidity & 7 & 8 & & & & 14 & & & \\
\hline
\end{tabular}

- Climate and weather information are available to the Nganyi community farmers but is not used. The broadcast system should include an application that sends information via an SMS module that ensures that the relevant information is delivered to the Nganyi community farmers

iii. Cost

- Decisions on weeding and harvesting can only be done when the farmer is present Information on the rainfall intensity, length of dry spells between rainfall, if any, rainfall after the dry spell and its intensity are necessary in deciding whether to plant again and what crop to plant. This information is not being used by the farmers to make informed decisions. $89 \%$ of the respondents indicated they owned a mobile phone and $94 \%$ of the respondents access their mobile phones daily hence the broadcast system should include this as the main mode of communication because in overall, an investment put into the land goes to waste when no or low yields are harvested.

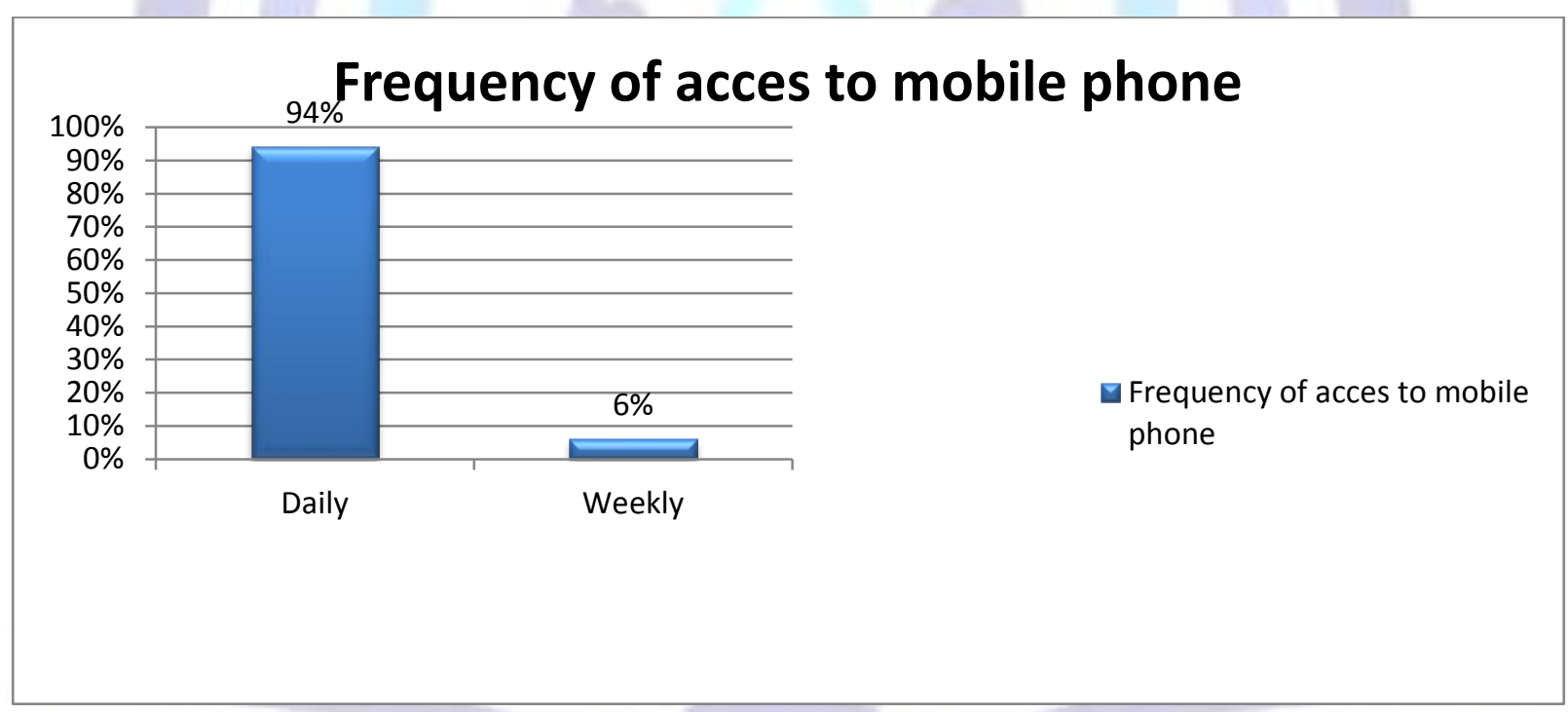

\section{Graph 1: Frequency of access to mobile phone. Source: Researcher}

\section{Generated Hypotheses}

Following this activity, the following hypotheses were generated arising from the analysis of the data collected in Step 2 \& 3.

- $\quad \mathrm{H} 1$ : Proliferation of mobile phones in rural communities means effective use

- $\quad \mathrm{H} 2$ : The rural community/environment technology gap is impacted by technology implementation

- H3: Existing mobile phone applications address the unique information needs of the rural user and therefore new mobile phone applications need not be developed or adapted from existing ones to meet these needs

\section{CONCLUTIONS}

We were able to validate that the mobile phone application for weather and climate prediction is appropriate for the rural farmer specifically the Nganyi community farmers. While this was a great achievement of research work, several issues were observed that lend to further work in this area. This section details achievements and areas for further research. The study answered the research questions we set out to achieve at the beginning:

1. Can creating knowledge alliances create better communication of weather and climate information? 
The process indicated that intensive dialogue between the scientific knowledge providers and user groups helped to define the strategies for bridging the knowledge systems. The study showed that farmers could be able to bridge the two different knowledge systems since they were used to operate in multiple cognitive frameworks. This collaborative information enabled Nganyi community farmers to make appropriate decisions for adaptation based on long-term, scientific weather forecasts.

2. Can weather forecasting systems be made more effective by linking indigenous rainmakers' knowledge and meteorological science?

This project helped researcher to understand that, to develop a system of forecasting weather and climate information at the village level by bridging the traditional and scientific knowledge there was need for a participatory approach to mobilize the farmers around the technology. Meteorological science was seen by the farmers as complicated and they did not understand the terms or the language used. Indigenous knowledge was seen as backward but was more reliable and understandable. A bridge between the two systems brought about the inclusion of merits of both systems into one. On the other hand, access, availability of infrastructure, skill and expertise was crucial to develop reliable region-specific scientific forecast to serve the farming societies.

3. What technologies can be incorporated to develop weather and climate broadcast system for the Nganyi community farmers?

Studies collected indicated that mobile phones were popular among the Nganyi community. This devise was available to $99 \%$ of community farmers. This paled in comparison to other devices such as computers, television and radios. Hence this was seen as the most suitable technology to use to communicate weather and climate information.

The study met the objectives set out at the beginning. The objectives of the study were:

1. To gain an expansive understanding of the diverse technology needs and perceptions of the target users in the local rural context.

Through an in-depth study of Nganyi community farmers and a comprehensive analysis of the results in a multidisciplinary way, we were able to identify information needs and perceptions of the users which guided this study to develop a mobile phone application for rural farmers in the local context.

2. To identify technology adoption and development methods that can be employed to inform an information dissemination structure relevant to the Nganyi community farmers.

The greatest achievement of this research work has been the involvement of critical stakeholders in development and subsequent validation of Weather and Climate Broadcast system that is useful in the rural context. We were also been able to demonstrate that due to the effects of the technology gap, the social-technical environment does not remain constant but rather continuously changes.

3. To develop a localized broadcast application to demonstrate the relevance of this research.

We have established that mobile phone applications need to be designed with the rural user context in mind to achieve effective use and acceptability.

Contributions to Research

1. The study clearly brought out the vast traditional knowledge of the farmers on rainfall prediction and their understanding on its reliability through their observation, experience and practice in the climate and weather.

2. Through an in-depth study of Nganyi community farmers and a comprehensive analysis of the results in a multidisciplinary way, we were able to identify information needs and perceptions of the users which guided this study to develop a mobile phone application for rural farmers in the local context.

Contributions to Public Policy

1. We have established that mobile phone applications need to be designed with the rural user context in mind to achieve effective use and acceptability.

2. The greatest achievement of this research work was the involvement of critical stakeholders in development and subsequent validation of Weather and Climate Broadcast system that is useful in the rural context.

We have established that the Nganyi Community Weather and Climate Broadcast system meets this need effectively. We therefore concluded that the research objectives have been met and the study has generated new hypothesis that may be examined as further work.

Main challenges faced

There were some methodological challenges to integrating indigenous and western scientific knowledge in furthering our understanding of climate change and deciding how and where the contribution of indigenous knowledge can be fully realized. For example, a formidable task was to determine where integration versus the exclusive application of local knowledge and western scientific knowledge is most appropriate. Even when it is appropriate to integrate the both local and western scientific knowledge, there are methodological problems with combining two fundamentally disparate knowledge systems. The challenge for all researchers is to determine when, where and how each knowledge system can contribute best. This worthy and complex discussion is a topic for further research. In the context of this present research, it is relevant that western scientific and Nganyi community rainmakers' knowledge are at once similar and different and therefore should be used both in conjunction and alternately in an iterative way.

Despite methodological challenges, my experience suggests that local knowledge has tremendous potential in providing very systematic, local, and detailed observations over a given period of time. These observations can contribute best both in and of themselves and as hypotheses for further research, as I have presented in this thesis.

Future work

As we can also see from the achievements listed above, this study has not only successfully met its objectives but has also opened more opportunities for further studies in this area. Having examined users during the entire research work, a number of issues came out, such as users typically interact with the system during testing and evaluation. This period is too short to quantify evidence regarding how useable such a system is meaningful in the long term hence the need for 
transforming evaluations. Additionally transforming evaluations enable researchers and developers to know more about how measures of effectiveness and satisfaction (Hornbaek K. 2005) develop over time. From these assessments our research has demonstrated that it is not possible to walk away after the first evaluation straight into design of software. The evaluation is not a single task, but a continuing activity which transforms and translates with each translation in the social-technical environment. Clearly, various aspects of evaluation progressively impact other aspects in a social technical network and cause some new form of translation. Translating evaluations are seen here to effectively address this challenge in our rural environments. This in turn informs evaluation of the design methodology used as well as evaluation of the design techniques used and finally, evaluation of the design solution.

Another area of interest that could be explored for further research would be investigation of whether indigenous peoples have agency in international negotiations and if so, how they have obtained it. Are indigenous community farmers able to directly participate in policy making and ensure that their views and concerns are reflected in the outcome? Agency here refers to the ability of actors to prescribe behavior and to substantively participate in and/or set their own rules related to the interactions between humans and their natural environment.

\section{ACKNOWLEDGMENTS}

My heartfelt gratitude goes to Dr. Daniel Orwa and Dr. Gilbert Ouma for their firm guidance throughout this research thesis. I would also like to thank Indigenous Knowledge expert, Dr. Maria Onyango for her valuable input on climate change; Chairman of the Rainmaker Association, Mr. Obedi Osore who was the local rainmaker and one of the community elders; my tour guide while in Kisumu, Joyce; farmers of the Nganyi Community who participated in the project and IT Consultant, Thomas Mbai for the opportunity to work together.

\section{REFERENCES}

1. Africa adapt. 2009. Integrating indigenous knowledge in climate risk management in support of community based adaptation. [ONLINE] Available at: http://www.africa-adapt.net/aa/ProjectOverview.aspx?PID=PUXVdbXh9bM\%3D. [Accessed 09 March 11]

2. Bartel, $\mathrm{COB}, 2010$. Enhancing food security in Africa through science, technology and innovation. UNCTAD Technology and Innovation Report 2010, [Online]. 1, xii. Available at: http://www.unctad.org/en/docs/tir2009_en.pdf [Accessed 20 January 2011].

3. Bayler \& Lewit, G.B. \& H.L., 1992. The Navy Operational Global and Regional Atmospheric Prediction Systems. Fleet Numerical Oceanography Center, [Online]. 273, $7 . \quad$ Available at: http://journals.ametsoc.org/doi/pdf/10.1175/1520-0434\%281992\%29007\%3C0273\%3ATNOGAR\%3E2.0.CO\%3B2 [Accessed 18 February 2011].

4. Burkman, E. (1987). Factors affecting utilization. In R. M. GagnÚ (Ed.) Instructional Technology: Foundations Hillsdale, NJ: Lawrence Erlbaum.

5. Cecchini, S. and Scott, C. 2003. "Can information and communications technology applications contribute to poverty reduction? Lessons from rural India", Information Technology for Development, (10), pp. 73-84.

6. Chalikov et al., D.C. et al., 1993. DYNAMIC COUPLING BETWEEN THIENMC GLOBAL ATMOSPHERE AND SPECTRAL WAVE MODELS. U.S. DEPARTMENT OF COMMERCE NATIONAL OCEANIC AND ATMOSPHERIC ADMINISTRATION NATIONAL WEATHER SERVICE NATIONAL METEOROLOGICAL CENTER, [Online]. Office Note 395, 66. Available at: http://www.emc.ncep.noaa.gov/officenotes/newernotes/on395.pdf [Accessed 24 February 2011]

7. Communications Commission of Kenya. 2010. Mobile phone subscribers inch closer to 20 million. [ONLINE] Available at: http://www.cck.go.ke/news/2010/news_30mar10.html. [Accessed 04 April 11].

8. Davidson, OD, 2003. The development and climate nexus: the case of sub-Saharan Africa. Climate Policy, [Online]. $\begin{array}{llllll}\text { Vol } & 3 & \text { (Supplement } & 1 \text { ), } & \text { S97-S113. } & \text { Available }\end{array}$ http://www.sciencedirect.com/science/article/pii/S1469306203001104 [Accessed 25 February 2011].

9. Davis, F. D. (1989), "Perceived usefulness, perceived ease of use, and user acceptance of information technology", MIS Quarterly 13(3): 319-340

10. Davis, F.D. 1993. "User acceptance of information technology: system characteristics, user perceptions and behavioral impacts", International Journal of Man-Machine Studies, (38:3), pp. 475-87.

11. Dekens, J. (2007a) Local Knowledge for Disaster Preparedness: A Literature Review. International Centre for Integrated Mountain Development, Kathmandu.

12. European Centre for Medium-Range Weather Forecasts (ECMWF). 2002. The early history of Numerical Weather Prediction. [ONLINE] Available http://www.ecmwf.int/products/forecasts/guide/The_early_history_of_Numerical_Weather_Prediction.html [Accessed 16 February 11].

13. Grimes, S. 2000. "Rural areas in the information society: diminishing distance or increasing learning capacity?" Journal of Rural Studies, (16:1), pp. 13-21.

14. Gurstein, M. (Ed.) 2000. Community informatics: enabling communities with information and communications technologies. Idea Group Publishers: Hershey, PA

15. Hansen, T.R 2006. Hansen Thomas Riisgaard, "Strings of Experiments - Looking at the Design Process as a Set of Socio-Technical Experiments", Proceedings of the ninth Participatory Design Conference 2006

16. Heeks, R. 2002. "I-development not e-development: special issue on ICTs and development", Journal of International Development, (14:1), pp. $1-11$.

17. Hollifield, C.A. and Donnermeyer, J.F. 2003. "Creating demand: influencing information technology diffusion in rural communities", Government Information Quarterly, (20), pp. 135-150. 
18. Ifatimehin, ooi, 2009. USING INDIGENOUS KNOWLEDGE IN LAND USE PLANNING AND MANAGEMENT: A PARTICIPATORY GIS APPROACH. Selected Works of Olarewaju Oluseyi Ifatimehin, [Online]. 19, 10. Available at: http://works.bepress.com/cgi/viewcontent.cgi?article=1018\&context=olarewaju ifatimehin\&seiredir=1\&referer=http\%3A\%2F\%2Fwww.google.com\%2Furl\%3Fsa\%3Dt\%26rct\%3D $\% 26 \mathrm{q} \% 3 \mathrm{Dthe} \% 2 \mathrm{Buse} \% 2 \mathrm{Bof} \%$ 2Bgis\%2Bin\%2Bintegrating\%2Bindegeneous\%2Bknowledge\%2Bin\%2Bland\%2Bsuitability\%2Bwaldron\%2Bn\%2Bs ui\%26source\%3Dweb\%26cd\%3D2\%26ved\%3D0CCoQFiAB\%26url\%3Dhttp\%253A\%252F\%252Fworks.bepress.co m\%252Fcgi\%252Fviewcontent.cgi\%253Farticle\%253D1018\%2526context\%253Dolarewaju ifatimehin\%26ei\%3Dn MXUTrOXCo o-

gat9sWaDw\%26usg\%3DAFQjCNHXt5TVTr 4RsHfUoCT3yjokOSu4A\%26cad\%3Drja\#search=\%22use\%20gis\%20i ntegrating\%20indegeneous\%20knowledge\%20land\%20suitability\%20waldron\%20n\%20sui\%22 [Accessed 28 November 2011].

19. Lai, V.S. 1994. "A survey of rural small business computer use: Success factors and decision support", Information \& Management, (26), pp. 297-304.

20. Legris, P., Ingham, J. and Collerette, P. 2003. "Why do people use information technology? A critical review of the technology acceptance model", Information \& Management, (40:3), pp. 191-204.

21. Lynch, Peter (2006). "Weather Prediction by Numerical Process". The Emergence of Numerical Weather Prediction. Cambridge University Press. pp. 1-27. ISBN 978-0-521-85729-1.

22. Lynch, Peter (March 2008). "The origins of computer weather prediction and climate modeling". Journal of Computational Physics (University of Miami) 227 (7): 3431-44. Bibcode 2008JCoPh.227.3431L. doi:10.1016/j.jcp.2007.02.034.

http://www.rsmas.miami.edu/personal/miskandarani/Courses/MPO662/Lynch,Peter/OriginsCompWF.JCP227.pdf. Retrieved 2010-12-23.

23. Mercer, jm, ik, It, ss, 2009. Framework for integrating indigenous and scientific knowledge for disaster risk reduction. Overseas Development Institute, [Online]. 1, 6-19. Available at: http://www.pacificdisaster.net/pdnadmin/data/original/Framewk intergratingindigenous scientific DRR.pdf [Accessed 28 November 2011].

24. Mitchell, S. and Clark, D. 1999. "Business adoption of information and communications technologies in the two-tier rural economy: some evidence from the South Midlands", Journal of Rural Studies, (15), pp. 447-455.

25. O'Neil, D. 2002. "Assessing community informatics: A review of methodological approaches for evaluating community networks and community technology centers", Internet Research, (12:1), pp. 76-102.

26. Organization for Economic Co-operation and Development (OECD). 2001. Information and Communication Technologies and rural development. OECD Publications: France

27. Othieno, JO, 2010. The weatherman is no magician. Daily Nation, 07 October. Opinion page.

28. Parikh, T.P. and P.J., 2006. Mobile phones and paper documents: Evaluating a new approach for capturing microfinance data in rural India (2006). Masters. Washington: University of Washington.

29. Parry, M.P., 2007. Climate Change 2007: impacts, adaptation and vulnerability: contribution of Working Group II to the fourth assessment report of the Intergovernmental Panel on Climate Change. 1st ed. United Nations Framework Convention on Climate Change (UNFCCC): Cambridge University Press.

30. Rao, S.S. 2004. "Role of ICTs in India's rural community information systems", Info, (6:4), pp. 261- 269.

31. Rogers, E. M. (1983). Diffusion of innovations. (3rd Ed.). New York: The Free Press.

32. Slack, F. and Rowley, J.E. 2004. "Challenges in the delivery of e-government through kiosks", Journal of Information Science, (30:4), pp. 369-377.

33. Staudenmaier, M.S. Jr, 1991. THE NAVY OPERATIONAL GLOBAL ATMOSPHERIC PREDICTION SYSTEM (NOGAPS) .WESTERN REGION TECHNICAL ATTACHMENT, [Online]. NO. 97-09, 5. Available at: http://www.wrh.noaa.gov/wrh/97TAs/TA9709/ta97-09.html [Accessed 24 February 2011].

34. Stoecker, R. 2005. "Is Community Informatics good for communities? Questions confronting an emerging field", The Journal of Community Informatics, (1:3), pp. 13-26.

35. Tripathi, nt et al., 2004. Integrating Indigenous Knowledge and GIS for participatory Natural Resource Management: State-of-the-practice. Overseas Development Institute, [Online]. 17/3, 5. Available at: http://www.ejisdc.org/ojs2/index.php/ejisdc/article/viewFile/105/105 [Accessed 28 November 2011].

36. UNCTAD 2006: UNCTAD (United Nations Conference on Trade and development), "Information Economy Report The Development perspective", 2006

37. United Nations Framework Convention on Climate Change, UNFCCC, (2007). Climate Change: Impacts Vulnerabilities and Adaptation in Developing Countries. In Buenos Aires programme of work on adaptation and response measures (decision 1/CP.10 of the Conference of the Parties to the UNFCCC) 2. Africa, Asia, Latin America, Small Island developing states, 2006-2007. United Nations Framework Convention on Climate Change (UNFCCC): United Nations Framework Convention on Climate Change (UNFCCC). 68.

38. Venkatesh, V.; Morris; Davis; Davis (2003), "User Acceptance of Information Technology: Toward a Unified View", MIS Quarterly, 27, pp. 425-478

39. Ventkatesh, et al 2006. Venkatesh V., Morris M., Davis G.B., Davis F.D, "User Acceptance of Information Technology: Toward a Unified View", MIS Quarterly Vol 27 No 3, 2006

40. Wessels, B. 2000. "Telematics in the East End of London", New media \& society, (2:4), pp. 427-444

\begin{tabular}{l} 
41. Wikipedia. 2010. Numerical weather prediction. [ONLINE] Available at: \\
\hline
\end{tabular} http://en.wikipedia.org/wiki/Numerical_weather_prediction [Accessed 17 February 11].

World Meteorological Organization, European Centre for Medium Range Weather Forecasts, WMO\&ECMWF, 1987. ECMWF: radiosonde data quality and monitoring: European Centre for Medium Range Weather Forecasts. 1st ed. Shinfield Park, Reading, RG29AX, U.K: ECMWF. 


\section{Authors' biography with Photo}
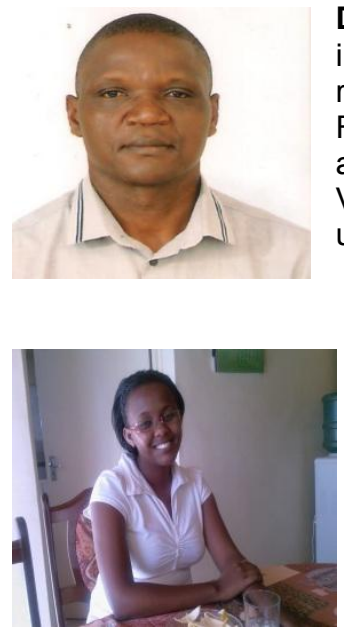

Dr. Daniel Orwa Ochieng is currently a Senior lecturer at the University of Nairobi. His research interests are in mobile phones in education, health, agriculture, ICT4D, M4D, ICT adoption among rural communities etc. Dr. Orwa is also a technical committee member of the International Federation of Information Processing (IFIP) representing Kenya, a publication reviewer with ICT4D and a member of Computer Society of Kenya, a professional member of ACM and member of VeSeL initiative among others. He has authored workshop and conferences papers as well as upcoming Journal paper and a book chapter.

understanding of Projects In Controlled Environment (PRINCE2)

Sharon Wanjiru Kamau is currently a Phd. Information Systems student at the University of Nairobi. Also holds a MSc Computer Science from University of Nairobi and an undergraduate degree in Business Information Technology from Strathmore University. A skilled professional with 10 years experience in Information and Communications Technology. Decisive, actionoriented and result focused. Extensive knowledge in systems administration with specific expertise in design, implementation and support of high-availability and high-reliability systems in critical business functions such as banking, microfinance and agriculture. Able to prioritize heavy workloads and capable of meeting deadlines. Is Oracle Certified Associate 11i and has good

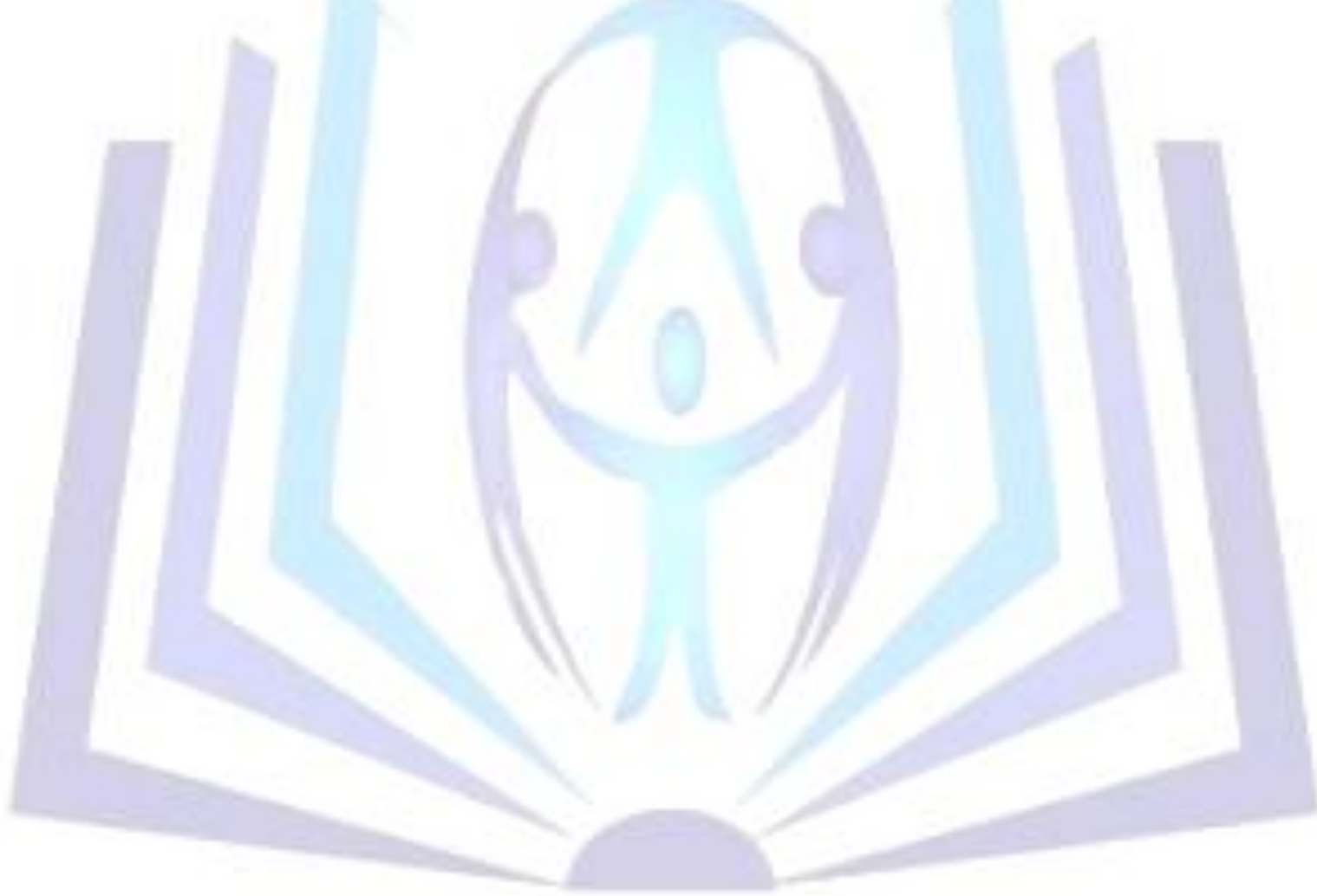

